\title{
Realization of a sustainable society by personal electric transportation and natural energy
}

\author{
Y. Miyamoto \\ Department of Environment and Energy, \\ Tohoku Institute of Technology, Japan
}

\begin{abstract}
Energy problem is a never-ending matter of life for us as we have limited resources to use. In modern times, energy problems have a great impact on the environment due to enormous and growing energy demand, and rapid depletion of fossil fuels that are largely consumed in transportation. It has become clear in the serious earthquake in East Japan that this depletion would raise a serious problem called WEB- Water, Energy, Bread (food). Of these, energy is a big problem in Japan. The energy self-sufficiency rate in Japan is 4\% which is less than $1 / 10^{\text {th }}$ of the food self-sufficiency rate in Japan i.e. $40 \%$. The purpose of this paper is to address possible resolutions to this problem. The migration from a large-scale centralized power generation system by conventional fossil fuel or nuclear power to a small scale distributed power generation system by natural energy, such as solar power and wind power, is one policy. The individuals and organizations covered by this energy system will be forced to be responsible for its management. If that happens, it is also necessary to review current energy consumption. The realization of a sustainable society, through the use of a modal shift by an independent power source, such as a personal transporter, proposed to be very effective, must be addressed. In addition, the energy of the future society, innovation of the use of natural energy and battery technology is a big key. In this paper the results from experimental results are described. Subsequently, in future work, "saving", "accumulation" and "production" of energy will be focused on. The theme of this paper is our experience in the serious earthquake in East Japan that led to the transition from fossil fuel and nuclear power to renewable smart energy, which must be now conveyed to the rest of the world.
\end{abstract}

Keywords: natural energy, modal shift, personal transportation, battery. 


\section{Introduction}

In regard to the energy sector in the modern period, two points were raised. First is a vast and growing energy demand, and second is the environmental impact associated with it. The enormous consumption of fossil fuel to the mobile unit is leading to its rapid depletion. Nuclear power is not the only problem. A modal shift that utilizes personal transporters and independent power, in order to realize a sustainable society, is very effective. The author proposes that the world will continue to work on this. Energy of the future society, innovation in battery technology and the use of natural energy is a big key. And it is also necessary in order to save on energy consumption.

\section{Personalization of mobile device}

Professor Mackay [1] is undertaking interesting research; in human subjects working for the average company in the UK, he has analysed the energy consumption of one person a day. Table 1 is an extension to this example

Table 1: $\quad$ Energy consumed by one person per day unit; kwh/person/day [1].

\begin{tabular}{|c|c|}
\hline 1.Public services & 4.0 \\
\hline 2. Transporting - stuff & 12 \\
\hline 3.Stuff & 48 \\
\hline 4.Food,farming,fertilizer & 15 \\
\hline $5 . \mathrm{Tv}$ & 1.7 \\
\hline $\begin{array}{l}\text { 6.Personal computer, } \\
\text { Video, Cleaner }\end{array}$ & 3.3 \\
\hline 7. Lighting (Home) & 2.7 \\
\hline 8. Lighting (Workshop) & 1.3 \\
\hline 9.Air-conditioner & 4.2 \\
\hline 10.Refrigerator & 2.7 \\
\hline 11. Electric carpet & 0.7 \\
\hline $\begin{array}{l}\text { 12. Warm water washing toilet } \\
\text { bowl }\end{array}$ & 0.7 \\
\hline 13.Tableware Clothes dryer & 0.7 \\
\hline $\begin{array}{l}\text { 14.Gas/Oil heating } \\
\text { (Warm.water - Cooking) }\end{array}$ & 28 \\
\hline 15.Jet flights & 30 \\
\hline 16. Car & 40 \\
\hline $\begin{array}{l}\text { Total } \\
\text { Hatching part is followed on tran } \\
\text { Its energy consumed is } 82 \mathrm{kwh} / \mathrm{pe}\end{array}$ & $\begin{array}{l}\text { 195kwh/person/day } \\
\text { on transportation. } \\
2 \mathrm{kwh} / \mathrm{person} / \text { day. }\end{array}$ \\
\hline
\end{tabular}


Japanese representative. Energy consumption associated with the movement, such as automobiles and transportation is more than $40 \%$. I know that it is important to think about the energy consumption associated with movement, especially considering the oil peak has been reached and running out of oil is seen as a certain problem in the decades ahead. It is even more so considering this reality. On the other hand, ensuring that means of movement is critical for humanity, it cannot be neglected. Comparing $\mathrm{CO}_{2}$ emissions according to the transportation of people, the environmental impact of the vehicle is about five times the railway. Therefore, the modal shift has been said to be a shift from car to rail. However, the inconvenience of switching to other transportation by rail is not improved. Therefore, for the shift to rail, there has not been so much support from the automobile. However, with one person to carry, moving the car with a weight of 1-2 tons is also contrary to the spirit of the Japanese admired by the world "mottainai" (saving). As a solution to this, there has recently been a focus on the electric vehicle. As shown in Figure 2, the fuel efficiency of the electric vehicle is about twice that of the gasoline engine car [2]. The electric vehicle uses energy efficiently and the electric car does not emit exhaust fumes; it is a clean vehicle. Solo-wheel and Segway ${ }^{\circledR}$ are types of personal transporters, designed for one person to ride 20-30 km. Solo-wheel and Segway ${ }^{\circledR}$ are devoid of a body configuration (as shown in Figure 1). A personal transporter rider is capable of running on bad roads and through bottlenecks. It can also run while talking to passengers and pedestrians. Conditions that cause congestion can also be loosened. The amount of charge for the same distance is less than one-tenth compared to an electric car, which the automaker is attempting to spread.

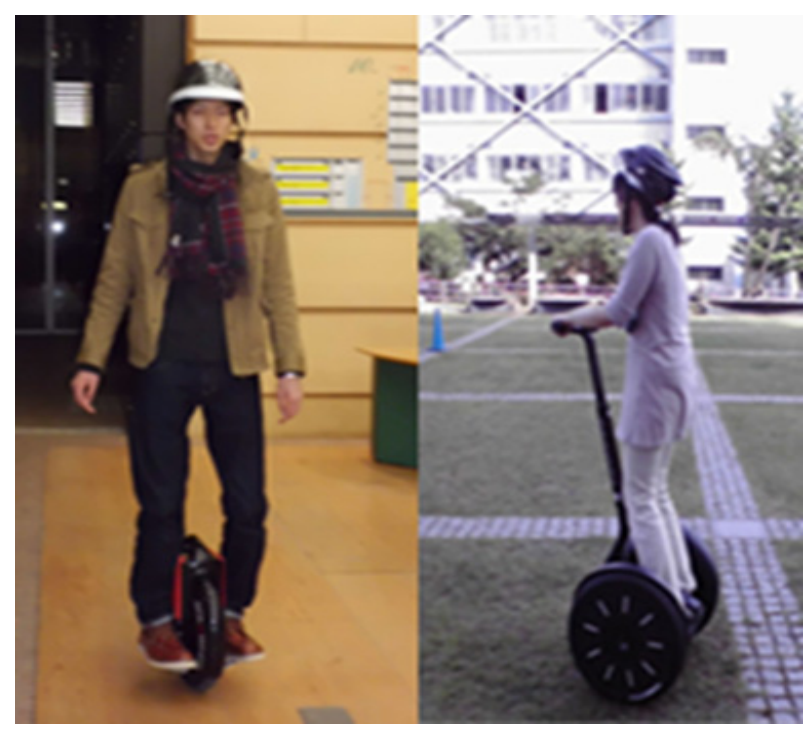

Figure 1: $\quad$ Personal transporter trial ride scenery. 


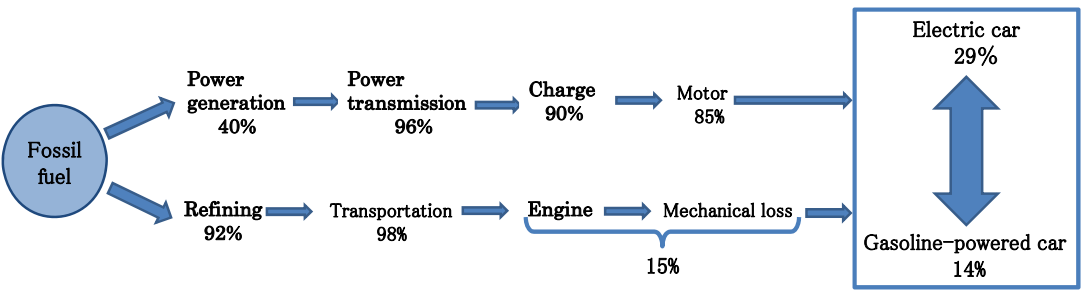

Figure 2: Fuel efficiency comparison of an electric car and a gasolinepowered car [2].

\section{Modal shift by the personal transporter and natural energy}

Kamioka [3] describes the effectiveness of the modal shift of transport systems. Figure 3 is an illustration of the $\mathrm{CO}_{2}$ emissions per unit volume and the number of passengers transported. The horizontal axis shows the number of persons per vehicle ride. The vertical axis shows the amount of $\mathrm{CO}_{2}$ emissions per km per person. The car is very familiar to us as many people utilize this vehicle. The bus or train can carry many people together. Therefore, $\mathrm{CO}_{2}$ emissions can be reduced per person per $\mathrm{km}$. That is why it is possible to take advantage of the bus and train instead of the car, so that there is a significant win for the guaranteed energy-saving and environmental affinity (as shown in Figure 3).

The Segway ${ }^{\circledR}$ is powered by lithium-ion batteries which typically take 8 to 10 hours to charge and consume $1.04 \mathrm{kwh}$ of energy from a wall outlet for a full battery charge. The Segway ${ }^{\circledR}$ offers riders a $26-39 \mathrm{~km}$ range on a single charge, depending on several factors, including terrain, payload, and riding style. Using the middle of this range, the Segway ${ }^{\circledR}$ consumes $0.032 \mathrm{kwh} / \mathrm{km}(1.04 \mathrm{kwh}$ $133 \mathrm{~km}$ ). Based on the average fuel mix for electricity production in Japan, those 32 watt-hours create $17.9 \mathrm{~g}$ of $\mathrm{CO}_{2}$ emissions per $\mathrm{km}[(0.032 \mathrm{kwh} / \mathrm{km}) \times(0.559$ $\mathrm{kg} \mathrm{CO} / \mathrm{kwh})=17.9 \mathrm{~g} \mathrm{CO}_{2}$. This value is one-sixth the amount of greenhouse gases emitted by an average Japanese car driving the same distance.

The above example is a calculated result of the use of conventional power. If we supply energy by configuring a system that utilizes natural energy such as that shown in Figure 4, the $\mathrm{CO}_{2}$ emissions would be zero, and subsequently an ultimate clean world can be achieved. The Segway ${ }^{\circledR}$ can run about $30 \mathrm{~km}$ a whole day if it is charged by solar panels of $4 \mathrm{~m}^{2}-$ it is the so-called personalization of electrical energy. Japan has about 70 million cars. There is a possibility that if $4 \%$ of car ownership changed to personalization, an alternative nuclear power will save all of 5 million $\mathrm{kw}$.

An independent power supply by solar power embodies four main features:

1) There are a small number of parts.

2) There are no moving parts (such as generators).

3) Smallness does not decrease efficiency.

4) Instability of the solar power output can be smoothed by a battery.

If you convert to using less batteries that can be connected directly, you can expect increased efficiency. In conjunction with improving the efficiency of 
solar panels, it is possible to charge a smaller area. By combining a personal transporter and solar power, the distributed energy system is achieved. This direction is consistent with the fact that people on their computers or phones become ubiquitous in society towards personalization. In the future, the Japanese system is to introduce a fixed price purchase of renewable energy. The modal shift will be more active as residential solar power spreads, and with increased use of natural energy such as wind power in the community.

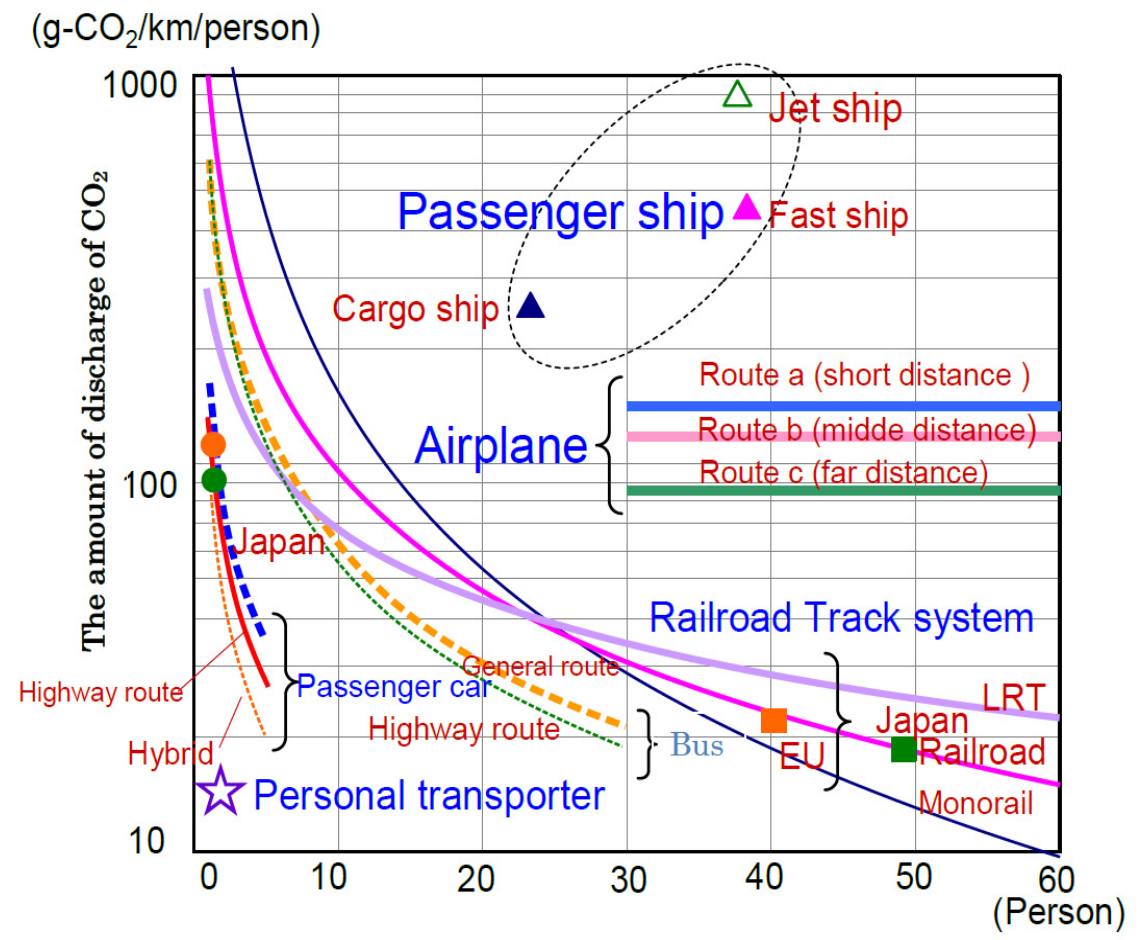

Figure 3: The modal shift of traffic system [3].
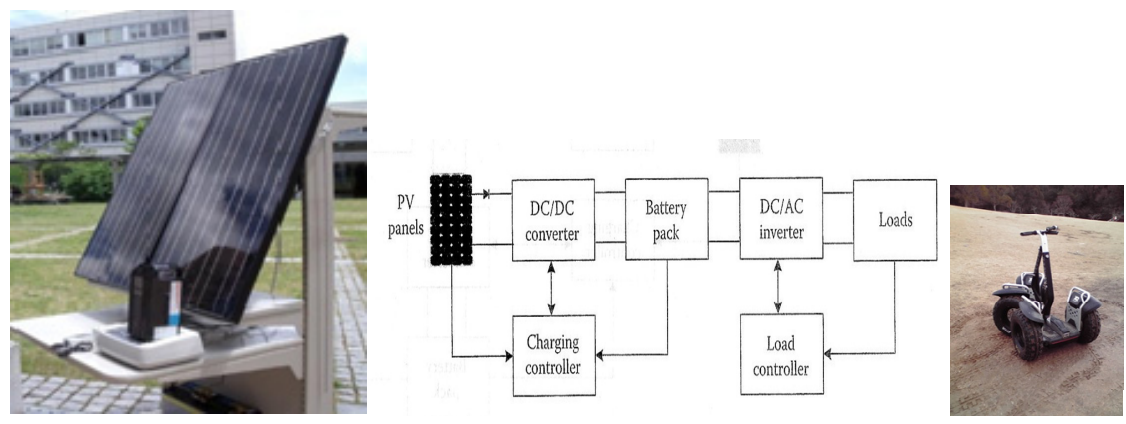

Figure 4: Independent power supply system by the use of natural energy. 


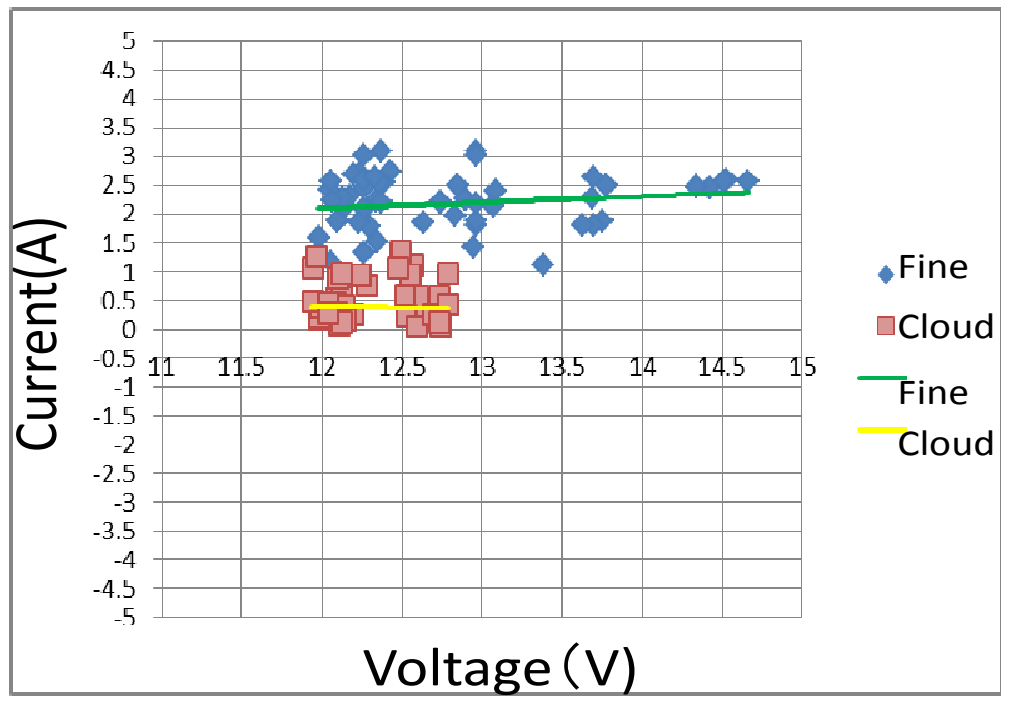

Figure 5: The voltage-current experimental characteristics of a solar panel in East Japan. The amount of rated max power is $70 \mathrm{w}$.

\section{Summary}

For the realization of a sustainable society, using a personal transporter with an independent power supply is a very effective modal shift which we must tackle. The research of "discovery", "accumulation" and "saving" in the field of energy will be important in the future. In particular, human resource development and innovation in battery technology is the key. A major shift in thinking is required as a big turning point. It is necessary to abandon arrogance and deception and seize crisis as an opportunity. From fossil fuels and nuclear power, and those of us who experienced the Great East Japan Earthquake, a smart transition to renewable energy is a serious topic which should go to the world now [4].

\section{References}

[1] David J C Mackay, Sustainable Energy - Without the Hot Air, UIT Cambridge Ltd., pp. 22-102, 2009.

[2] Hiroshi Shimizu, New EV, Ohmsha, pp. 10-12, 1987.

[3] Naomi Kamioka, Railways save the Earth, Traffic Newspaper Co., pp. 6575, 2007.

[4] Yuichi Miyamoto, Shun Sasaki and Kenta Kakizakai, Modal shift by personal electric transportation and natural energy, Journal of the Society of Environmental Instrumentation, Control and Automation, 17 (2/3), pp. 112$115,2012$. 